\title{
THERMAL STUDY OF FOUR IRRADIATED IMIDAZOLINE DERIVATIVES IN SOLID STATE
}

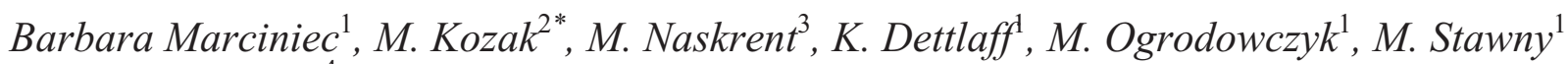 \\ and L. Wachowski ${ }^{4}$ \\ ${ }^{1}$ Department of Pharmaceutical Chemistry, Poznań University of Medical Sciences, Gruwaldzka 6, 60-780 Poznań, Poland \\ ${ }^{2}$ Department of Macromolecular Physics, A. Mickiewicz University, Umultowska 85, 60-614 Poznań, Poland \\ ${ }^{3}$ Department of Medical Physics, A. Mickiewicz University, Umultowska 85., 60-614 Poznań, Poland \\ ${ }^{4}$ Department of Cooridinational Chemistry, A. Mickiewicz University, Gruwaldzka 6, 60-780 Poznań, Poland
}

\begin{abstract}
Four imidazoline derivatives: antazoline ( $\mathrm{AN})$, naphazoline $(\mathrm{NN})$, tymazoline (TM), xylometazoline (XM), in the form of hydrochlorides in solid phase have been subjected to high energy e-beam irradiation from an accelerator $(\sim 10 \mathrm{MeV})$ at a dose varied from 25 to $200 \mathrm{kGy}$. The effects of the irradiation have been assessed by DSC, X-ray diffraction, FTIR, EPR and TLC.

The standard sterilisation dose of $25 \mathrm{kGy}$ has been found to produce changes in the properties of one derivative (XM), two other ones ( $\mathrm{AN}$ and TM) have been found sensitive to doses $>100 \mathrm{kGy}$, whereas NN has been resistant to irradiation in the whole range studied (25-200 kGy). EPR results indicated that the changes taking place in the therapeutic substances studied are related to radical formation. The irradiation induced changes in colour, a decrease or increase in the melting point, changes in the XRD pattern, small changes in the shape of FTIR peaks and the presence of radiolysis products. The XM compounds cannot be sterilised by irradiation because of the radiation induced changes in its physico-chemical properties.
\end{abstract}

Keywords: antazoline, DSC, EPR, FTIR, naphazoline, TLC, tymazoline, XRD, xylometazoline

\section{Introduction}

Differential scanning calorimetry (DSC) has been recently often used in analysis of medicaments [1-19]. For many years it has been an important tool in the study of drug polymorphism [2-6]. This area of study is very important not only from the technological but also from the pharmacological point of view as different polymorphous forms can have different physical properties such as density, solubility, melting point and hence may be characterised by different bioavailability [7]. Many authors recommend this method for investigation of phase equilibria in multicomponent systems and for detection of inconsistencies between two biologically active substances [8] or between the therapeutic substance and emollients used in drug formulation technology [9-12]. The DSC method has been also appreciated by the authors working on evaluation of stability of therapeutic substances [13-19]. It has been successfully applied in estimation of the thermal [13], photochemical [14] and radiochemical stability of drugs [15-21]. Determination of the radiochemical stability of therapeutic substances (and emollients) has become of increasing importance in view of growing application of radia- tion sterilisation, an effective method of sterilisation and decontamination of drugs [22]. Particularly important is determination of the radiochemical stability of therapeutic substances being components of eye drops and ophthalmic ointments [21], injections and infusion fluids and drugs applied to open injuries and burns as they must be sterile $[22,23]$. The four selected derivatives of imidazoline show antihistamine activity (AN, TM) or $\alpha$-adrenergic activity (NN, XM). They are components of popular eye drops, nose drops, gels and aerosols, or injections (AN). The aim of the study was assessment of these compounds resistance to e-beam irradiation used for radiation sterilisation.

\section{Experimental}

\section{Materials}

The material studied were four commercially available imidazoline derivatives in substantia, satisfying the pharmacopoeia $[24,25]$ demands.

\footnotetext{
* Author for correspondence: mkozak@amu.edu.pl
} 


\section{Methods}

\section{Exposure to irradiation}

Approximately $0.5 \mathrm{~g}$ of substance was placed in colourless glass jar of $5 \mathrm{~mL}$ volume and closed with a plastic stopper. The samples in the vials were exposed to irradiation in a linear electron accelerator LAE 13/9 (electron beam $9.96 \mathrm{MeV}$ and current intensity $6.2 \mu \mathrm{A})$ till they absorbed a dose of 25, 50, 100 and 200 kGy [24-26].

\section{Organoleptic analysis}

Before and after irradiation the compound was subjected to organoleptic analysis comparing its colour (against a white background), form, odour, solubility and clarity of solution to those of the non-irradiated sample [24, 25].

\section{Scanning electron microscopy (SEM)}

SEM analysis was performed on a SEM 515 (Philips) electron microscope with $14 \mathrm{~mm}$ working distance and $3-10 \mathrm{kV}$ accelerating voltage.

\section{X-ray diffraction (XRD)}

X-ray analysis was performed on a Philips powder diffractometer model PW 1070 controlled by an IBM PC unit, using $\mathrm{CuK}_{\alpha}$ radiation $(35 \mathrm{kV}, 20 \mathrm{~mA})$ and a nickel filter. The patterns were recorded for $5^{\circ}<2 \theta<50^{\circ}$ for the gaps of $1^{\circ} / 1^{\circ}$ at a counter step $0.02^{\circ} \mathrm{s}^{-1}$. All XRD measurements were carried in an air atmosphere.

\section{Infrared spectroscopy (FTIR)}

A $\mathrm{KBr}$ disc was prepared by mixing $1.00 \mathrm{mg}$ of a substance with $300 \mathrm{mg}$ of $\mathrm{KBr}$ and compressing it with Pye Unicam minipress. The spectra were recorded using a Bruker FT-IR spectrometer in the range of $400-4000 \mathrm{~cm}^{-1}$ with $\mathrm{KBr}$ as a blank.

\section{Electron paramagnetic resonance (EPR)}

The EPR experiments were carried out for non-irradiated and irradiated samples, in standard EPR quartz sample tubes from Wilmad. The measurements were performed with a Bruker EPR EMX-10 spectrometer working at $9.4 \mathrm{GHz}$ (X-band) at room temperature $(293 \quad \mathrm{~K})$. The sensitivity of the spectrometer is $1 \cdot 10^{10}$ spins per gram. Induction of the magnetic field was measured to an accuracy of $0.001 \mathrm{mT}$. Microwave frequency was measured to an accuracy of $0.001 \mathrm{GHz}$. The spectrometer operating conditions during the experiment were: modulation amplitude of
$0.1 \mathrm{mT}$, microwave power of $2 \mathrm{~mW}$ and sweep width of $20 \mathrm{mT}$.

Thin layer chromatography (TLC)

Plates of the size $5.0 \times 20.0 \mathrm{~cm}$, covered with silica gel Kisegel $60 \mathrm{~F}_{254}$ were used. The mobile phases were used:

A. benzene - acetone $-25 \%$ ammonia $(3: 25: 3)$;

B. 2-propanol - toluene - $25 \%$ ammonia $(3: 2: 1)$;

C. 1,4-dioxan-xylene-toluene-2-propanol-25\% ammonia (1:2:1:4:2). The traces were set with a quartz lamp working at $\lambda=254 \mathrm{~nm}$.

\section{Differential scanning calorimetry (DSC)}

The measurements were performed using a Netzsch model 204 Phoenix instrument. The samples of about $3-5 \mathrm{mg}$ were sealed in aluminium cells with pierced lids. The measurement were performed in helium atmosphere in temperatures from 20 to $300^{\circ} \mathrm{C}$ at a scanning rate of $5^{\circ} \mathrm{C} \mathrm{min}^{-1}$. The results were processed using TA (Netzsch) program. For the determination of the enthalpy values of the representative phase transitions, linear or tangent-sigmoidal baselines were used.

\section{Results and discussion}

Four selected derivatives of imidazoline in the form of solid-state hydrochlorides have been subjected to e-beam irradiation in the doses of 25, 50, 100 and $200 \mathrm{kGy}$.

The first noted effect of irradiation was a change in colour of three of them: XM, AN and TM. XM changes its colour from white to pale yellow already upon irradiation with a dose of $25 \mathrm{kGy}$, and the intensity of the yellow colour increases with increasing dose of irradiation. Upon irradiation with doses up to $100 \mathrm{kGy} \mathrm{AN}$ and TM did not change colour and remained white, after irradiation with $100 \mathrm{kGy}$ AN became pale pink and TM became pale yellow. No changes in colour were observed for the fourth derivative that is $\mathrm{NN}$, even upon irradiation with a dose of $200 \mathrm{kGy}$.

No changes attributable to irradiation were observed in the phase, smell, solubility and clarity of water solutions of all four irradiated compounds.

As evidenced by the SEM photographs (Fig. 1), the compounds studied in solid phase occur in crystallites of different shape and size. NN and AN occur in the form of the best developed and largest crystals, XM and TM appear as poorer developed and more refined crystals. A comparison of the SEM photos taken of the initial samples and those 

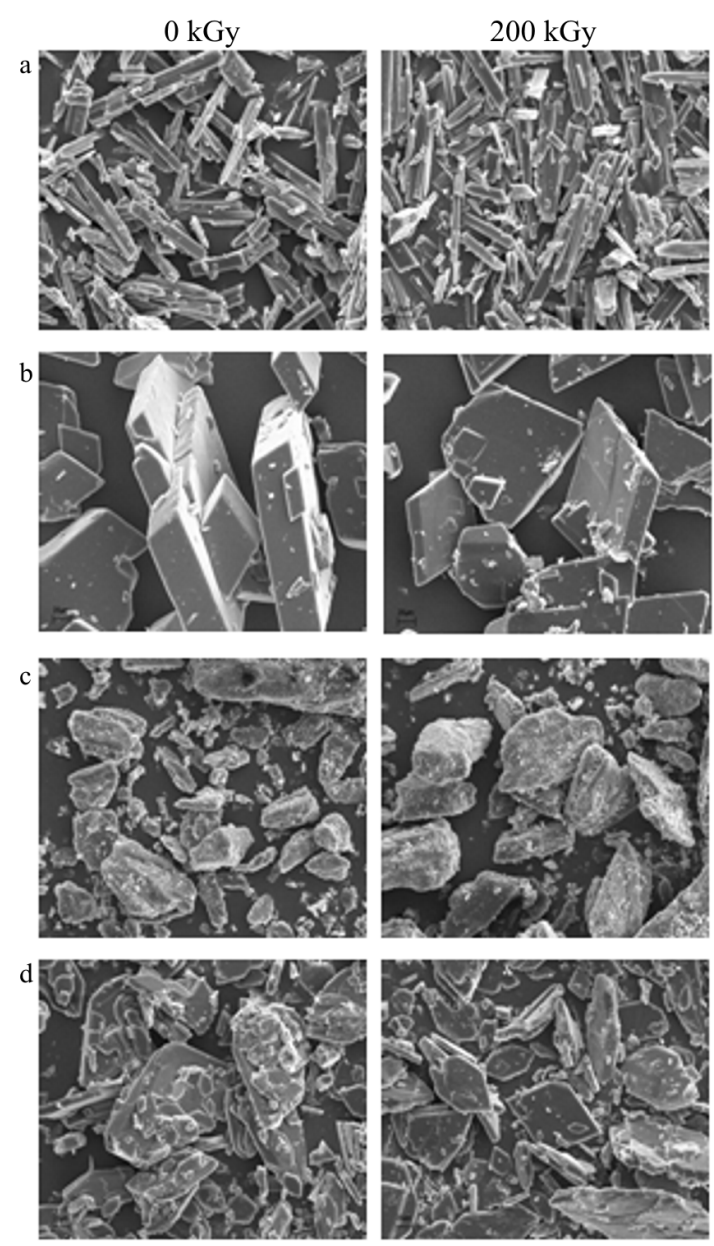

$\stackrel{\longmapsto}{100 \mu \mathrm{m}}$

Fig. 1 SEM photographs of the compounds examined before and after irradiation (200 kGy): a - antazoline,

$\mathrm{b}$ - naphazoline, $\mathrm{c}$ - tymazoline, $\mathrm{d}$-xylometazoline

irradiated with a dose of $200 \mathrm{kGy}$, revealed no changes induced by irradiation.

To check the effect of irradiation on the crystal structure of the derivatives studied, they were subjected to XRD analysis. The XRD patterns were recorded for the initial substances and for the same substances exposed to irradiation with a dose of 200 kGy (Fig. 2). The general character of the patterns remains unchanged. Small changes in the intensity of certain peaks could be observed for AN and XM, while slightly more profound changes for TM and NN. The XRD pattern of irradiated NN also revealed a change in the shape of one peak (Fig. 2).

As the changes appear only as a decrease or increase in intensity of single peaks it is reasonable to conclude that ionising radiation has only small effect on the crystalline structure of the compounds studied.

At the next step of the study, the compounds before and after irradiation with a dose of $100 \mathrm{kGy}$ were subjected to FTIR measurements. The character

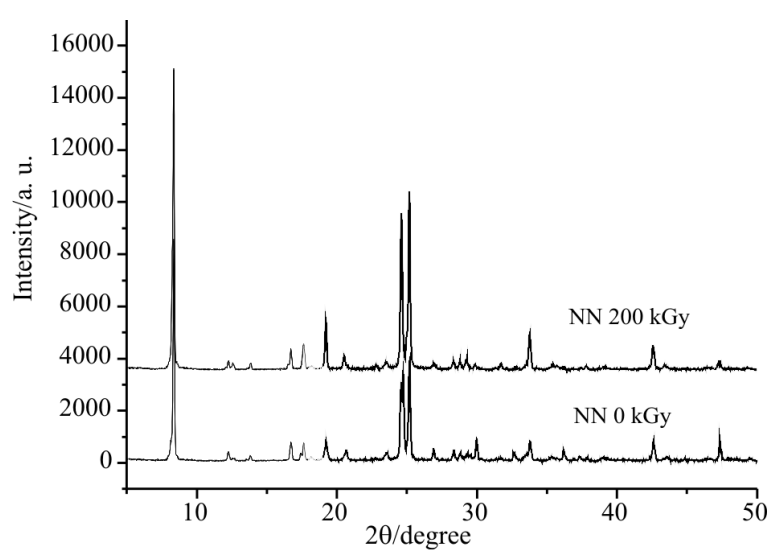

Fig. 2 X-ray powder diffraction patterns of naphazoline before and after irradiation

of the FTIR spectra of the compounds studied, recorded before and after irradiation, in the range 4000 to $400 \mathrm{~cm}^{-1}$, was unchanged, that is no significant changes manifested as shifts, changes in the shape or intensity of peaks were observed. Small changes were observed in the spectrum of naphazoline in the range $2800-3000 \mathrm{~cm}^{-1}$ and in that of TM in the same range and additionally in the range $400-1000 \mathrm{~cm}^{-1}$. They could be a result of changes in the position of the methylene bridge and thus in the position of the imidazoline ring with respect to the plane of the other rings $\left(2800-3000 \mathrm{~cm}^{-1}\right)$ and in the mutual position of the benzene ring substituents $\left(1000-500 \mathrm{~cm}^{-1}\right)$ in TM.

In order to explain the character of changes taking place in the process of radiodegradation, the substances studied were subjected to electron paramagnetic resonance (EPR) measurements. The EPR spectra showed no signals from the non-irradiated crystalline imidazoline derivatives. Figure 3 shows exemplary EPR spectra of AN, NN, TM and XM taken immediately after their irradiation with a dose of $25 \mathrm{kGy}$. The EPR spectra were measured immediately after irradiation and subsequently several times over a period of six months. Changes over time were observed in the line intensities and shapes. The stability of the radicals in the irradiated imizadoline derivatives samples was also studied. The signal intensity decay data obtained for a sample irradiated at the dose $25 \mathrm{kGy}$ were used to get the decay characteristics of the radicals. In AN, NN, TM and $\mathrm{XM}$ upon absorption of $25 \mathrm{kGy}$, the amounts of $7.23 \cdot 10^{14}, 1.43 \cdot 10^{14}, 2.00 \cdot 10^{14}$ and $61.81 \cdot 10^{14}$ spins per gram were generated, respectively, as measured directly after irradiation.

To find out whether the presence of free radicals could lead to subsequent reactions and appearance of radiolysis products the thin layer chromatography (TLC) was applied. Three products of radiolysis were 
detected in irradiated XM $\left(R_{\mathrm{f}}=0.14, R_{\mathrm{f}}=0.57, R_{\mathrm{f}}=0.90\right.$, phase $\mathrm{A})$ and one product in irradiated $\mathrm{AN}\left(R_{\mathrm{f}}=0.92\right.$, phase A). In irradiated NN and TM no radiolysis products were detected even after their irradiation with a dose of $200 \mathrm{kGy}$.

The results obtained for $\mathrm{AN}$ and $\mathrm{XM}$ are consistent with those of organoleptic analysis, assuming that the changes in colour can be related to
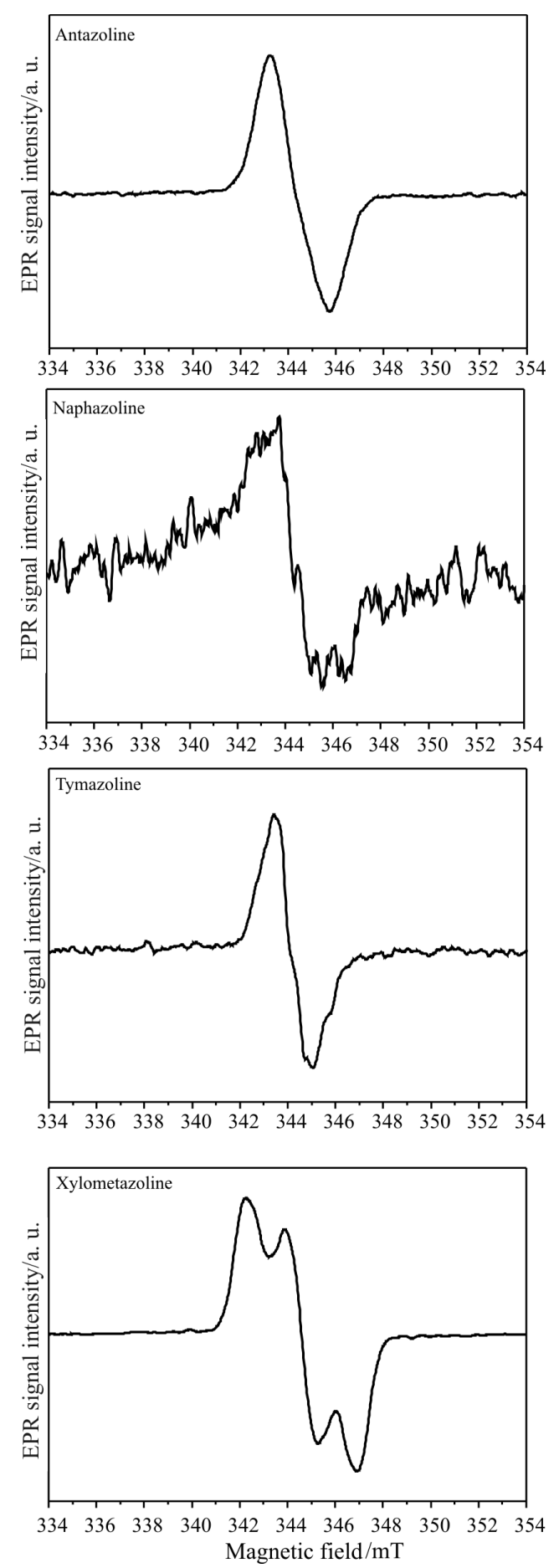

Fig. 3 EPR spectra of antazoline, naphazoline, tymazoline and xylometazoline after irradiation ( $25 \mathrm{kGy})$ the appearance of the radiolysis products. However, no such correlation was found for TM, which becomes yellow as a result of irradiation but no products of its radiolysis were detected by the TLC method.

At this stage of our investigation the compounds studied were subjected to differential scanning calorimetry. This very sensitive method was applied to confirm no radiolysis of TM, if yes the DSC spectrum of TM taken before and after irradiation should be the same and the melting point of this compound should be unchanged. The DSC spectra of TM were recorded before irradiation and after irradiation with each of the doses considered. The spectra taken after irradiation were, however, found to show a distinctly notable decrease in the melting point proportional to the dose applied: from $0.1^{\circ} \mathrm{C}$ for the dose of $25 \mathrm{kGy}$ to the value of $3.1^{\circ} \mathrm{C}$ for the dose of $200 \mathrm{kGy}$ (Fig. 4, Table 1). This result proves that TM undergoes radiolysis and the radiolysis products are responsible for the decrease in its melting point, but probably the TLC method is not sensitive enough to detect their presence. The DSC spectrum of irradiated NN shows insignificant changes in the melting point with respect to that in the spectrum of non-irradiated compound, which confirm that this substance is resistant to ionising irradiation and does not undergo radiolysis as evidenced by the TLC results. The DSC spectrum of XM shows an increase in its melting point, while that of AN a decrease in its melting point. A considerable increase in the melting point of irradiated XM is a phenomenon we have observed for the first time in our investigation of radiolysis of therapeutic substances [16-21]. It is supposed that this increase is related to a considerable radiolysis of this compound (three radiolysis products detected by TLC) and a high concentration of the radicals formed (the highest from among the compounds studied in this work). For antrazoline an additional effect was observed.

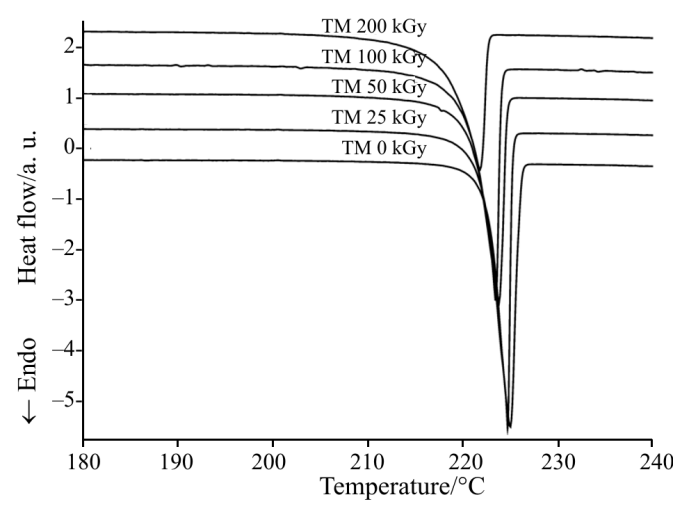

Fig. 4 The DSC curves obtained for tymazoline before and after irradiation 
Table 1 Melting enthalpies and characteristic temperatures from DSC data

\begin{tabular}{|c|c|c|c|c|c|}
\hline \multirow{2}{*}{ Compound } & \multicolumn{5}{|c|}{$T_{\text {peak }} /{ }^{\circ} \mathrm{C}$} \\
\hline & 0 kGy & $25 \mathrm{kGy}$ & 50 kGy & $100 \mathrm{kGy}$ & $200 \mathrm{kGy}$ \\
\hline AN & $247.3 ; 248.1 ; 249.1$ & $247.1 ; 248.0$ & 247.1 & 247.1 & - \\
\hline $\mathrm{NN}$ & 259.7 & 259.3 & 259.4 & 259.9 & - \\
\hline TM & 224.9 & 224.8 & 223.8 & 223.5 & 221.8 \\
\hline \multirow[t]{2}{*}{$\mathrm{XM}$} & 314.1 & 318.7 & 318.1 & 323.3 & 317.5 \\
\hline & \multicolumn{5}{|c|}{$T_{\text {onset }} /{ }^{\circ} \mathrm{C}$} \\
\hline AN & 245.4 & 245.2 & 245.1 & 244.8 & - \\
\hline $\mathrm{NN}$ & 257.5 & 257.5 & 257.4 & 257.9 & - \\
\hline $\mathrm{TM}$ & 222.6 & 221.9 & 220.6 & 220.6 & 218.2 \\
\hline \multirow[t]{2}{*}{$\mathrm{XN}$} & nd & nd & - & nd & nd \\
\hline & \multicolumn{5}{|c|}{$\Delta H / \mathrm{J} \mathrm{g}^{-1}$} \\
\hline AN & -179.5 & -174.2 & -170.1 & -161.8 & - \\
\hline $\mathrm{NN}$ & -165.7 & -166.3 & -159.1 & -158.9 & - \\
\hline $\mathrm{TM}$ & -144.9 & -145.3 & -136.4 & -140.2 & -122.5 \\
\hline XM & nd & nd & - & nd & nd \\
\hline
\end{tabular}

nd - no determined

The DSC curve of the initial sample shows three maxima $\left(T_{\text {peak }}=247.3 ; 248.1 ; 249.1^{\circ} \mathrm{C}\right)$. For the sample irradiated with a dose of $25 \mathrm{kGy}$ the DSC curve had only two maxima (at 247.1 and $248.0^{\circ} \mathrm{C}$ ), and the DSC curves of the samples irradiated with higher doses had only one maximum at about $247.1^{\circ} \mathrm{C}$.

For the samples studied we also determined changes in the enthalpy of melting accompanying the irradiation. Similarly as in our earlier studies, with increasing irradiation dose the enthalpy of melting decreased. The most profound change was observed for TM for which the difference between the nonirradiated sample and the sample irradiated with a dose of $100 \mathrm{kGy}$ reached $15.5 \%$. For XM the determination of the change in the enthalpy of melting was impossible because the melting occurred together with decomposition.

\section{Conclusions}

According to the results collected in Table 2, XM is the least resistant (the most sensitive) to ionising radiation, while $\mathrm{NN}$ is the most resistant (the least sensitive) to it. Taking into account the amount of free radicals and the changes observed for the compounds studied by the other methods it can be reasonably supposed that these changes are related to the concentration of the free radicals, which is the highest in XM and the lowest in NN. Assuming that the concentration of free radicals can be a criterion of radiochemical stability, the compounds studied can be ordered as follows according to increasing resistance to ionising irradiation: $\mathrm{XM}<\mathrm{AN}<\mathrm{TM}<\mathrm{NN}$.

In conclusion, it is highly probable that the radiochemical stability of the imidazoline derivatives studied is determined mainly by their chemical

Table 2 Compilation of the results obtained after irradiation the imidazoline derivatives

\begin{tabular}{|c|c|c|c|c|c|c|c|}
\hline \multirow[b]{2}{*}{ Compound } & \multicolumn{7}{|c|}{ Analytical results } \\
\hline & SEM & IR & TLC & $\begin{array}{l}\text { Organoleptic } \\
\text { analysis }\end{array}$ & DSC & XRD & EPR \\
\hline $\mathrm{XM}$ & - & - & $\begin{array}{c}+ \\
3 \text { radiolysis } \\
\text { products }\end{array}$ & white $\rightarrow$ yellow & $\stackrel{+}{T_{\text {peak }}}$ & + & + \\
\hline AN & - & - & $\begin{array}{c}+ \\
1 \text { radiolysis } \\
\text { products }\end{array}$ & white $\rightarrow$ pink & $\stackrel{+}{\downarrow} T_{\text {peak }}$ & + & + \\
\hline TM & - & -+ & - & white $\rightarrow$ yellow & $\stackrel{+}{T_{\text {peak }}}$ & + & + \\
\hline $\mathrm{NN}$ & - & -+ & - & - & - & + & + \\
\hline
\end{tabular}


structure, crystallinity and the concentration of free radicals formed upon irradiation.

NN characterised by the simplest structure, forming large crystals and producing the lowest concentration of free radicals on irradiation is the most radiochemically stable, while $\mathrm{XM}$ of the most spatially developed structure, forming fine crystallites and producing the highest concentration of free radicals is the lest radiochemically stable.

\section{References}

1 M. Wesołowski, J. Thermal Anal., 38 (1992) 2239.

2 A. Rossi, A. Savioli, M. Bini, D. Capsoni, V. Massarotti, R. Bettini, A. Gazzaniga, M. E. Sangalli and F. Giordano, Thermochim. Acta, 406 (2003) 55.

3 M. R. Caira, K. A. Alkhamis and R. M. Obaidat, J. Pharm. Sci., 93 (2004) 601.

4 D. Giron, M. Draghi, C. Goldbronn, S. Pfeffer and P. Piechocki, J. Thermal Anal., 49 (1995) 537.

5 M. Bartolomei, M. Bertocchi, C. Ro and E. C. Signoretti, Thermochim. Acta, 321 (1998) 43.

6 M. Wesołowski, Farmacja Polska, 56 (2000) 3.

7 M. Wesołowski and T. Konarski, Farmacja Polska, 54 (1998) 121.

8 M. M. Varma and J. K. Pandi, Drug Dev. Ind. Pharm., $31(2005) 417$.

9 P. Mura, P. Gratteri and M. T. Faucci, J. Therm. Anal. Cal., 68 (2002) 541.

10 C. M. Fernandes, M. T. Vieira and F. J. B. Veiga, Eur. J. Pharm. Sci., 15 (2000) 79.

11 F. Castelli, C. Messina, M. G. Sarpietro, R. Pignatello and G. Puglisi, Thermochim. Acta, 400 (2003) 227.

12 G. Bruni, L. Amici, V. Berbenni, A. Marini and A. Orlandi, J. Therm. Anal. Cal., 68 (2002) 561.
13 N. S. Fernandes, M. A. da Silva Carvalho Filho, R. A. Mendes and M. Ionashiro, J. Braz. Chem. Soc., 10 (1999) 459.

14 B. D. Glass, Cs. Novák and M. E. Brown, J. Therm. Anal. Cal., 77 (2004) 1013.

15 B. Kartusin-Razem, K. Hamitouche, N. Maltar-Strmecki, K. Kos, I. Pucic, S. Britvic-Budicin and D. Razem, Radiat. Phys. Chem., 73 (2005) 111.

16 B. Marcinie, Z. Płotkowiak, L. Wachowski, M. Kozak and M. Popielarz-Brzezińska, J. Therm. Anal. Cal., 68 (2002) 423.

17 B. Marciniec, M. Kozak, L. Wachowski and M. Ogrodowczyk, J. Therm. Anal. Cal., 73 (2003) 473.

18 T. Kryczka, B. Marciniec, M. Popielarz-Brzezinska, M. Bero, J. Kasperczyk, P. Dobrzyński, Z. Kazimierczuk and P. Grieb, J. Control. Rel., 89 (2003) 447.

19 B. Marciniec, M. Kozak and K. Dettlaff, J. Therm. Anal. Cal., 77 (2004) 305.

20 B. Marciniec, M. Kozak and M. Ogrodowczyk, J. Therm. Anal. Cal., 77 (2004) 581.

21 B. Marciniec, M. Stawny, M. Kozak and M. Naskrent, J. Therm. Anal. Cal., 84 (2006) 741.

22 B. Marciniec and K. Dettlaff, Radiation Sterilization of Drugs in Report of International Atomic Energy Agency, Trends in Radiation Sterilization, Vienna 2005.

23 M. L. Botelho, M. C. Godinho, M. Partidario and M. E. Andrade, Radiat. Phys. Chem., 42 (1993) 605.

24 Pharmacopoea Polonica, Editio VI (2002).

25 European Pharmacopeia $3^{\text {rd }}$ Ed. (1997), Supplement (2000).

26 EN 552:1994, Sterilisation of medical devices - validation and routine control of sterilisation by irradiation.

DOI: $10.1007 / \mathrm{s} 10973-006-8060-\mathrm{x}$ 